\title{
Risk Factors for Sleep Problems Prior to Radiochemotherapy for Malignant Gliomas
}

\author{
SVENJA KOPELKE ${ }^{1,2}$, TROELS W. KJAER ${ }^{3}$, SOEREN TVILSTED ${ }^{4}$, \\ STEVEN E. SCHILD ${ }^{5}$, TOBIAS BARTSCHT ${ }^{2}$ and DIRK RADES ${ }^{1}$ \\ ${ }^{1}$ Department of Radiation Oncology, University of Lübeck, Lübeck, Germany; \\ ${ }^{2}$ Department of Hematology and Oncology, University of Lübeck, Lübeck, Germany; \\ ${ }^{3}$ Department of Neurology, Zealand University Hospital, Roskilde, Denmark; \\ ${ }^{4}$ Research Projects and Clinical Optimization, Zealand University Hospital, Koege, Denmark; \\ ${ }^{5}$ Department of Radiation Oncology, Mayo Clinic, Scottsdale, AZ, U.S.A.
}

\begin{abstract}
Background/Aim: Many patients with malignant gliomas are scheduled for radiochemotherapy, which may cause emotional distress associated with sleep problems. This study aimed to determine the prevalence of such sleep problems in these patients and identify risk factors. Patients and Methods: Fifty-seven patients scheduled for radiochemotherapy for grade II-IV gliomas were retrospectively investigated for pre-treatment sleep problems. Fifteen characteristics were evaluated including temporal relation to COVID-19 pandemic, age, gender, performance status, comorbidity, (family) history of malignancies, distress score, emotional problems, physical problems, practical problems, involved sites, glioma grade, upfront surgery, and corticosteroids. Results: Nineteen patients stated pre-treatment sleep problems (prevalence $=66.7 \%$ ). Significant associations with sleep problems were found for female gender $(p=0.023)$, presence of emotional problems $(p=0.006)$, and $\geq 4$ physical problems $(p<0.001)$. A trend was found for distress scores $\geq 5$ ( $p=0.077)$. Conclusion: The prevalence of sleep problems was high. Risk factors were determined that can be used to identify patients who likely benefit from psychological support.
\end{abstract}

According to the classification of the World Health Organization (WHO), the group of gliomas includes four

This article is freely accessible online.

Correspondence to: Professor Dirk Rades, MD, Department of Radiation Oncology, University of Lübeck, Lübeck, Ratzeburger Allee 160, 23562 Lübeck, Germany. Tel: +49 45150045401, Fax: +49 45150045404, e-mail: dirk.rades@uksh.de

Key Words: Malignant glioma, radiochemotherapy, sleep problems, prevalence, risk factors. grades (grades I to IV), of which grade IV tumors (glioblastoma multiforme) are the most aggressive lesions with a 5-year survival rate of about 5\% (1-3).

Neurosurgical resection should be performed whenever safely possible. In patients with grade III or IV gliomas, resection is generally followed by radiochemotherapy (4-6). This applies also to selected patients with grade II gliomas, mainly after incomplete resection. Assignment to a course of radiochemotherapy may cause significant distress for the patients who may be afraid particularly of the exposure to radiation and potential treatment-related adverse events (7-10). The distress may lead to sleep problems that can significantly impair the patients' quality of life and require psychological support already prior to the start of radiochemotherapy (11-13). Therefore, the present study investigated the prevalence and potential risk factors of pre-treatment sleep problems in patients with grade II to IV gliomas assigned to radiochemotherapy. These data can contribute to the identification of patients who would likely benefit from psychological support beginning already prior to their course of radiochemotherapy.

\section{Patients and Methods}

In this retrospective study, 57 patients scheduled for radiochemotherapy of WHO grade II-IV gliomas were investigated with respect to pre-treatment sleep problems. These patients had completed the National Comprehensive Cancer Network (NCCN) Distress Thermometer $(14,15)$ between February 2019 and March 2021. The study was approved as a part of a larger project by the Ethics Committee of the University of Lübeck (reference 21-284). The technique to be used for the planned radiotherapy was volumetricmodulated arc therapy (VMAT). The preferred dose-fractionation regimen for grade III and grade IV gliomas was 59.4 Gy in 33 fractions of $1.8 \mathrm{~Gy}$. In case of involvement of the brain stem, total doses were reduced to 55.8 Gy or $57.8 \mathrm{~Gy}$. For grade II lesions, the preferred regimen was $54.0 \mathrm{~Gy}$ in 30 fractions of $1.8 \mathrm{~Gy}$. Finally, three patients did not receive the complete planned dose due to tumor 
progression or other complications during the course of radiotherapy. Fifty-four patients $(94.7 \%)$ of the patients received chemotherapy in addition to their radiation treatment, mostly with temozolomide (16).

Fifteen characteristics (Table I) were investigated for potential associations with the occurrence of pre-treatment sleep problems including temporal relation to the Coronavirus Disease 2019 (COVID-19) pandemic (prior to vs. during the pandemic), age ( $\leq 58$ $v s . \geq 59$ years, median age $=59$ years), gender (female $v s$. male), Karnofsky performance score ( $\leq 60 v s . \geq 70)$, Charlson comorbidity index (2-4 vs. $\geq 5$ ), history of another malignancy (no $v s$. yes), family history of malignancy (no $v s$. yes), distress score (0-4 vs. $\geq 5$ ), emotional problems (no $v s$. yes), number of physical problems $(0-3 v s . \geq 4)$, practical problems (no $v s$. yes), number of involved sites ( $1 v s . \geq 2$ ), WHO grade (II-III vs. IV), upfront surgery (no $v s$. yes), and treatment with corticosteroids at the time of evaluation with the (NCCN) Distress Thermometer (no vs. yes). Emotional, physical and practical problems were assessed with the $(\mathrm{NCCN})$ Distress Thermometer $(14,15)$. The statistical analyses regarding the associations between the 15 investigated characteristics and occurrence of pre-treatment sleep problems were performed with the Fisher's exact test. $p$-Values of less than 0.05 were considered significant, and $p$-values of less than 0.10 indicated a trend.

\section{Results}

Nineteen of the 57 patients stated sleep problems prior to their planned course of radiochemotherapy, corresponding to a prevalence of $66.7 \%$. Significant associations with occurrence of sleep problems were found for female gender $(p=0.023)$, presence of emotional problems $(p=0.006)$, and $\geq 4$ physical problems $(p<0.001)$ (Table II). In addition, a trend was found for distress scores $\geq 5(p=0.077)$. The temporal relation to the COVID-19 pandemic did not show a significant association with pre-treatment sleep problems $(p=0.78)$ (Table II).

\section{Discussion}

The majority of patients with grade III or IV gliomas and selected patients with grade II gliomas are scheduled for radiochemotherapy, mainly following neurosurgical resection (4-6). This situation may produce significant emotional distress for the patients due to fears regarding the treatment procedure, potential side effects, and unsatisfactory treatment outcomes including progression or recurrence of the glioma (7-10, 17-19). These fears may lead to sleep problems that can significantly impair the patients' quality of life (11-13). Affected patients would likely benefit from near-term psychological support. However, no study could be identified in the literature that focused particularly on sleep problems prior to radiochemotherapy of gliomas.

The present study aimed to contribute to filling this gap to some extent by evaluating the prevalence of pre-treatment sleep problems and potential risk factors in patients with grade II-IV gliomas assigned to radiochemotherapy. The prevalence of pre-treatment sleep disorders was $66.7 \%$ and higher than in patients with solid cancers such as breast
Table I. Evaluated patient and tumor characteristics.

\begin{tabular}{|c|c|c|}
\hline Characteristic & Subgroup & $\begin{array}{c}\text { Frequency, } \\
\mathrm{n}(\%)\end{array}$ \\
\hline \multirow[t]{2}{*}{ COVID-19 pandemic } & Before & $33(58)$ \\
\hline & During & $24(42)$ \\
\hline \multirow[t]{2}{*}{ Age } & $\leq 58$ Years & $29(51)$ \\
\hline & $\geq 59$ Years & $28(49)$ \\
\hline \multirow[t]{2}{*}{ Gender } & Female & $25(44)$ \\
\hline & Male & $32(56)$ \\
\hline \multirow[t]{2}{*}{ Karnofsky performance score } & $\leq 60$ & $10(18)$ \\
\hline & $\geq 70$ & $47(82)$ \\
\hline \multirow[t]{2}{*}{ Charlson comorbidity index } & $2-4$ & $38(67)$ \\
\hline & $\geq 5$ & $19(33)$ \\
\hline \multirow[t]{3}{*}{ History of another malignancy } & No & $50(88)$ \\
\hline & Yes & $6(11)$ \\
\hline & Unknown & $1(2)$ \\
\hline \multirow[t]{3}{*}{ Family history of malignancy } & No & $30(53)$ \\
\hline & Yes & $26(46)$ \\
\hline & Unknown & $1(2)$ \\
\hline \multirow[t]{2}{*}{ Distress-score } & $0-4$ & $20(35)$ \\
\hline & $\geq 5$ & $37(65)$ \\
\hline \multirow[t]{2}{*}{ Emotional problems } & No & $16(28)$ \\
\hline & Yes & $41(72)$ \\
\hline \multirow[t]{2}{*}{ Number of physical problems } & $0-3$ & $24(42)$ \\
\hline & $\geq 4$ & $33(58)$ \\
\hline \multirow[t]{2}{*}{ Practical problems } & No & $25(44)$ \\
\hline & Yes & $32(56)$ \\
\hline \multirow[t]{2}{*}{ Number of involved sites } & 1 & $41(72)$ \\
\hline & $\geq 2$ & $16(28)$ \\
\hline \multirow[t]{2}{*}{ WHO Grade } & II-III & $14(25)$ \\
\hline & IV & $43(75)$ \\
\hline \multirow[t]{2}{*}{ Upfront surgery } & No & $13(23)$ \\
\hline & Yes & 44 (77) \\
\hline \multirow[t]{3}{*}{ Corticosteroids } & No & $27(47)$ \\
\hline & Yes & $29(51)$ \\
\hline & Unknown & $1(2)$ \\
\hline
\end{tabular}

COVID-19: Coronavirus Disease 2019; WHO: World Health Organization.

cancer $(42.3 \%)$, gynecological cancers $(46.8 \%)$, head-andneck-cancers (42.7\%), and prostate cancer (20.8\%) (20-23). Moreover, the prevalence in the current study was higher than in a study of patients with recurrent glial neoplasms $(46.8 \%)$, in a study evaluating patients with glioma following surgical resection $(33.7 \%)$, and in a study evaluating sleep problems during the year prior to the diagnosis of adult glioma $(41 \%)(11,24,25)$. However, due to the different settings, it does not appear reasonable to compare these data to the results of our present study.

In addition to the determination of the prevalence of sleep problems prior to radiochemotherapy, the current study aimed to identify risk factors for sleep problems. Significant associations were found between the occurrence of sleep problems and female gender, emotional problems, and physical problems. Moreover, a trend was observed for higher distress scores. Some of these findings agree with the results of a 
Table II. Associations between characteristics and pre-treatment sleep problems.

\begin{tabular}{|c|c|c|c|c|}
\hline \multirow[b]{2}{*}{ Characteristic } & & \multicolumn{2}{|c|}{ Sleep disorders, $\mathrm{n}(\%)$} & \multirow[b]{2}{*}{$p$-Value } \\
\hline & & Yes $(n=38)$ & No $(n=19)$ & \\
\hline \multirow[t]{2}{*}{ COVID-19 pandemic } & Before & $21(55)$ & $12(63)$ & 0.78 \\
\hline & During & $17(45)$ & $7(37)$ & \\
\hline \multirow[t]{2}{*}{ Age } & $\leq 58$ Years & $18(47)$ & $11(58)$ & 0.58 \\
\hline & $\geq 59$ Years & $20(53)$ & $8(42)$ & \\
\hline \multirow[t]{2}{*}{ Gender } & Female & $21(55)$ & $4(21)$ & 0.023 \\
\hline & Male & $17(45)$ & $15(79)$ & \\
\hline \multirow[t]{2}{*}{ Karnofsky performance score } & $\leq 60$ & $8(21)$ & $2(11)$ & 0.47 \\
\hline & $\geq 70$ & $30(79)$ & $17(89)$ & \\
\hline \multirow[t]{2}{*}{ Charlson comorbidity index } & $2-4$ & $24(63)$ & $14(74)$ & 0.56 \\
\hline & $\geq 5$ & $14(37)$ & $5(26)$ & \\
\hline \multirow[t]{2}{*}{ History of another malignancy } & No & $34(92)$ & $16(84)$ & 0.40 \\
\hline & Yes & $3(8)$ & $3(16)$ & \\
\hline \multirow[t]{2}{*}{ Family history of malignancy } & No & $20(54)$ & $10(53)$ & $>0.99$ \\
\hline & Yes & $17(46)$ & $9(47)$ & \\
\hline \multirow[t]{2}{*}{ Distress-score } & $0-4$ & $10(26)$ & $10(53)$ & 0.077 \\
\hline & $\geq 5$ & $28(74)$ & $9(47)$ & \\
\hline \multirow{2}{*}{ Emotional problems } & No & $6(16)$ & $10(53)$ & 0.006 \\
\hline & Yes & $32(84)$ & $9(47)$ & \\
\hline \multirow[t]{2}{*}{ Number of physical problems } & $0-3$ & $9(24)$ & $15(79)$ & $<0.001$ \\
\hline & $\geq 4$ & $29(76)$ & $4(21)$ & \\
\hline \multirow[t]{2}{*}{ Practical problems } & No & $14(37)$ & $11(58)$ & 0.16 \\
\hline & Yes & $24(63)$ & $8(42)$ & \\
\hline \multirow[t]{2}{*}{ Number of involved sites } & 1 & $28(74)$ & $13(68)$ & 0.76 \\
\hline & $\geq 2$ & $10(26)$ & $6(32)$ & \\
\hline \multirow[t]{2}{*}{ WHO Grade } & II-III & $9(24)$ & $5(26)$ & $>0.99$ \\
\hline & IV & $29(76)$ & $14(74)$ & \\
\hline \multirow[t]{2}{*}{ Upfront surgery } & No & $11(29)$ & $2(11)$ & 0.18 \\
\hline & Yes & $27(71)$ & $17(89)$ & \\
\hline \multirow[t]{2}{*}{ Corticosteroids } & No & $19(51)$ & $8(42)$ & 0.58 \\
\hline & Yes & $18(49)$ & $11(58)$ & \\
\hline
\end{tabular}

COVID-19: Coronavirus Disease 2019; WHO: World Health Organization. Significant $p$-values given in bold.

prospective cohort study of adult patients with newly diagnosed glioma receiving active management (26). This study investigated emotional distress and found that sleep problems was one of the most frequently reported causes of distress. Distress scores (14) were comparably high in patients who were functionally impaired (physical problems) and in patients who were depressed (emotional problem) (24). Moreover, in the study investigating insomnia in patients with recurrent glial neoplasms, trends were observed for an association between insomnia and fatigue (physical problem) (11). Associations between higher distress scores and sleep problems prior to radiotherapy or radiochemotherapy were shown for patients with breast cancer, prostate cancer, and rectal or anal cancer $(20$, $22,27)$. A trend for an association between pre-radiotherapy sleep problems and female gender was also reported for patients irradiated for rectal or anal cancer (27). However, since our present study can be considered unique, as it is the first study evaluating sleep problems prior to radiochemotherapy in patients with malignant gliomas, its results may not be directly compared to studies that included differing tumor types. Moreover, when interpreting, the retrospective study design should be considered.

In conclusion, the prevalence of sleep problems prior to radiochemotherapy for gliomas was high. The risk factors that were determined in this study can be used to identify patients who likely benefit from psychological support offered already prior to the start of treatment.

\section{Conflicts of Interest}

On behalf of all Authors, the corresponding Author states that there are no conflicts of interest related to this study.

\section{Authors' Contributions}

S.K., T.W.K., S.T., T.B. and D.R. designed the study; S.K. provided the data that were analyzed by S.E.S. and D.R.; S.K., S.E.S. and D.R. drafted the article, which was reviewed and approved by all Authors. 


\section{Acknowledgements}

As part of the project NorDigHealth, this study was funded by the European Regional Development Fund through the Interreg Deutschland-Danmark program.

\section{References}

1 Louis DN, Perry A, Reifenberger G, von Deimling A, FigarellaBranger D, Cavenee WK, Ohgaki H, Wiestler OD, Kleihues P and Ellison DW: The 2016 World Health Organization classification of tumors of the central nervous system: a summary. Acta Neuropathol 131(6): 803-820, 2016. PMID: 27157931. DOI: 10.1007/s00401-016-1545-1

2 Alexander BM and Cloughesy TF: Adult glioblastoma. J Clin Oncol 35(21): 2402-2409, 2017. PMID: 28640706. DOI: 10.1200/JCO.2017.73.0119

3 Delgado-López PD and Corrales-García EM: Survival in glioblastoma: a review on the impact of treatment modalities. Clin Transl Oncol 18(11): 1062-1071, 2016. PMID: 26960561. DOI: $10.1007 / \mathrm{s} 12094-016-1497-\mathrm{x}$

4 Stupp R, Brada M, van den Bent MJ, Tonn JC, Pentheroudakis $\mathrm{G}$ and ESMO Guidelines Working Group: High-grade glioma: ESMO Clinical Practice Guidelines for diagnosis, treatment and follow-up. Ann Oncol 25(Suppl 3): iii93-ii101, 2014. PMID: 24782454. DOI: 10.1093/annonc/mdu050

5 Witteler J, Schild SE and Rades D: Prognostic factors of local control and survival in patients irradiated for glioblastoma multiforme (GBM). Anticancer Res 40(12): 7025-7030, 2020. PMID: 33288598. DOI: $10.21873 /$ anticanres.14728

6 Witteler J, Kjaer TW, Tvilsted S, Schild SE and Rades D: Reevaluation of prognostic factors for survival after radiotherapy of cerebral gliomas: a supplementary analysis to a previous study. Anticancer Res 40(11): 6513-6515, 2020. PMID: 33109591. DOI: 10.21873/anticanres.14674

7 Rydelius A, Lätt J, Kinhult S, Engelholm S, Van Westen D, Pihlsgård M, Bengzon J, Sundgren PC and Lilja Å: Longitudinal study of cognitive function in glioma patients treated with modern radiotherapy techniques and standard chemotherapy. Acta Oncol 59(9): 1091-1097, 2020. PMID: 32847475. DOI: 10.1080/0284186X.2020.1778181

8 Wang Q, Xiao F, Qi F, Song X and Yu Y: Risk factors for cognitive impairment in high-grade glioma patients treated with postoperative radiochemotherapy. Cancer Res Treat 52(2): 586593, 2020. PMID: 32019288. DOI: 10.4143/crt.2019.242

9 Mantilla EC Jr, Abramowitz J, Dan TU and Pan E: Prolonged steroid dependence in adult patients with glioma. Anticancer Res 40(4): 2059-2064, 2020. PMID: 32234897. DOI: 10.21873/ anticanres.14163

10 Lawrie TA, Gillespie D, Dowswell T, Evans J, Erridge S, Vale L, Kernohan A and Grant R: Long-term neurocognitive and other side effects of radiotherapy, with or without chemotherapy, for glioma. Cochrane Database Syst Rev 8: CD013047, 2019. PMID: 31425631. DOI: 10.1002/14651858. CD013047.pub2

11 Robertson ME, McSherry F, Herndon JE and Peters KB: Insomnia and its associations in patients with recurrent glial neoplasms. Springerplus 5(1): 823, 2016. PMID: 27390663. DOI: $10.1186 / \mathrm{s} 40064-016-2578-6$
12 Gustafsson M, Edvardsson T and Ahlström G: The relationship between function, quality of life and coping in patients with lowgrade gliomas. Support Care Cancer 14(12): 1205-1212, 2006. PMID: 16710652. DOI: 10.1007/s00520-006-0080-3

13 Teng KX, Price B, Joshi S, Alukaidey L, Shehab A, Mansour K, Toor GS, Angliss R and Drummond K: Life after surgical resection of a low-grade glioma: A prospective cross-sectional study evaluating health-related quality of life. J Clin Neurosci 88: 259267, 2021. PMID: 33992194. DOI: 10.1016/j.jocn.2021.03.038

14 Holland JC, Andersen B, Breitbart WS, Buchmann LO, Compas B, Deshields TL, Dudley MM, Fleishman S, Fulcher CD, Greenberg DB, Greiner CB, Handzo GF, Hoofring L, Hoover C, Jacobsen PB, Kvale E, Levy MH, Loscalzo MJ, McAllisterBlack R, Mechanic KY, Palesh O, Pazar JP, Riba MB, Roper K, Valentine AD, Wagner LI, Zevon MA, McMillian NR and Freedman-Cass DA: Distress management. J Natl Compr Canc Netw 11(2): 190-209, 2013. PMID: 23411386. DOI: 10.6004/ jncen.2013.0027

15 Mehnert A, Müller D, Lehmann C and Koch U: Die deutsche Version des NCCN Distress-Thermometers. Zeitschrift für Psychiatrie, Psychologie und Psychotherapie 54(3): 213-223, 2021. DOI: $10.1024 / 1661-4747.54 .3 .213$

16 Stupp R, Mason WP, van den Bent MJ, Weller M, Fisher B, Taphoorn MJ, Belanger K, Brandes AA, Marosi C, Bogdahn U, Curschmann J, Janzer RC, Ludwin SK, Gorlia T, Allgeier A, Lacombe D, Cairncross JG, Eisenhauer E, Mirimanoff RO, European Organisation for Research and Treatment of Cancer Brain Tumor and Radiotherapy Groups and National Cancer Institute of Canada Clinical Trials Group: Radiotherapy plus concomitant and adjuvant temozolomide for glioblastoma. $\mathrm{N}$ Engl J Med 352(10): 987-996, 2005. PMID: 15758009. DOI: 10.1056/NEJMoa043330

17 Rades D, Witteler J, Leppert J and Schild SE: Re-irradiation for recurrent glioblastoma multiforme. Anticancer Res 40(12): 70777081, 2020. PMID: 33288605. DOI: 10.21873/anticanres.14735

18 Végváry Z, Darázs B, Paczona V, Dobi Á, Reisz Z, Varga Z, Fodor E, Cserháti A, Oláh J, Kis D, Barzó P and Hideghéty K: Adaptive radiotherapy for glioblastoma multiforme - The impact on disease outcome. Anticancer Res 40(8): 4237-4244, 2020. PMID: 32727750. DOI: 10.21873/anticanres.14425

19 Marchionni A, Palumbo I, Montesi G, Bini V, Zucchetti C, Cenci N, Chiarini P, Saccia S, Aristei C and Lupattelli M: Fractionated stereotactic sequential boost in a selected cohort of glioblastoma patients: a mono-institutional analysis. Anticancer Res 40(6): 33873393, 2020. PMID: 32487635. DOI: 10.21873/anticanres.14322

20 Kopelke S, Bartscht T, Schild SE, Tvilsted S, Kjaer TW and Rades D: Frequency and risk factors of sleep disturbances in patients with prostate cancer assigned to local or loco-regional radiotherapy. Anticancer Res 41(10): 5165-5169, 2021. PMID: 34593468. DOI: 10.21873/anticanres.15334

21 Rades D, Kopelke S, Soror T, Schild SE, Tvilsted S, Kjaer TW and Bartscht T: Sleep disorders prior to adjuvant radiation therapy for gynecological malignancies. Anticancer Res 41(9): 4407-4410, 2021. PMID: 34475061. DOI: 10.21873/anticanres. 15246

22 Rades D, Narvaez CA, Schild SE, Tvilsted S and Kjaer TW: Sleep disorders before and during the COVID-19 pandemic in patients assigned to adjuvant radiotherapy for breast cancer. In Vivo 35(4): 2253-2260, 2021. PMID: 34182504. DOI: 10.21873/ invivo. 12498 
23 Rades D, Kopelke S, Soror T, Bartscht T, Tvilsted S, Kjaer TW and Schild SE: Risk factors for sleep disturbances in patients scheduled for radiotherapy of head-and-neck cancer. Anticancer Res 41(10): 5065-5069, 2021. PMID: 34593456. DOI: 10.21873/ anticanres. 15322

24 Huang Y, Jiang ZJ, Deng J and Qi YJ: Sleep quality of patients with postoperative glioma at home. World J Clin Cases $8(20)$ : 4735-4742, 2020. PMID: 33195641. DOI: 10.12998/wjcc. v8.i20.4735

25 Peeters MCM, Dirven L, Koekkoek JAF, Gortmaker EG, Fritz L, Vos MJ and Taphoorn MJB: Prediagnostic symptoms and signs of adult glioma: the patients' view. J Neurooncol 146(2): 293-301, 2020. PMID: 31894516. DOI: 10.1007/s11060-019-03373-y
26 Rooney AG, McNamara S, Mackinnon M, Fraser M, Rampling $\mathrm{R}$, Carson A and Grant R: The frequency, longitudinal course, clinical associations, and causes of emotional distress during primary treatment of cerebral glioma. Neuro Oncol 15(5): 635643, 2013. PMID: 23444258. DOI: 10.1093/neuonc/not009

27 Rades D, Kopelke S, Bartscht T, Schild SE, Tvilsted S and Kjaer TW: Evaluation of pre-radiotherapy sleep disorders in patients with rectal or anal cancer. Anticancer Res 41(9): 4439-4442, 2021. PMID: 34475066. DOI: 10.21873/anticanres.15251

Received October 15, 2021

Revised November 2, 2021

Accepted November 3, 2021 